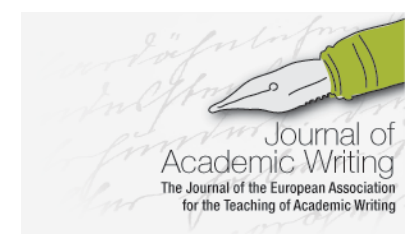

Journal of Academic Writing Vol. 8 No 2 Winter 2018, pages 48-66 http://dx.doi.org/10.18552/joaw.v8i2.496

\title{
Redesigning a Discipline-Specific Writing Assignment to Improve Writing on an EMI Programme of Engineering
}

\author{
Andreas Eriksson \\ Chalmers University of Technology, Sweden
}

\begin{abstract}
English-medium instruction (EMI) in higher education presents challenges at many different levels for educators and students. One of the challenges is disciplinary writing, as students typically study disciplinary content through, and also write in, English as a second or a foreign language. The present, exploratory intervention study uses the redesign of a writing assignment in a Master's level engineering course at a Swedish university to investigate challenges of disciplinary writing in an EMI context. The study describes how collaboration between content and communication staff helped unpack some of the challenges that students faced. The results show that the students' texts improved and that the redesign helped them to better adjust to a genre partially new to them. The study also underscores the value for programmes to have a clear plan for writing. The planning is likely to benefit from collaboration between disciplinary and communication faculty, as these participants bring different knowledge to the process.
\end{abstract}

\section{Introduction}

The steady increase of courses and programmes taught in English in higher education contexts where the first language is not English, has put communication and communication-intensive activities at the centre of many higher education debates. This type of teaching and learning situation, also known as English-Medium Instruction (EMI) or English-Medium Education (EME), has generated discussions and research about, for instance: teacher training and EMI certification (Dimova 2017, Kling and Stæhr 2011), the influence of EMI on students' learning of content knowledge (Airey 2010, Doiz, Lasagabaster and Sierra 2013), students' development of their knowledge of English (Aguilar and Muñoz 2014, Knoch et al. 2015), and pedagogical consequences of teaching in an EMI context (Smit and Dafouz 2012). The field is further complicated by the fact that EMI-related studies feature under various acronyms (for example, English for Academic Purposes (EAP), English for Specific Purposes (ESP), Integrating Content and Language in Higher Education (ICLHE) and Content and Language Integrated Learning (CLIL); see Gustafsson and Jacobs (2013) and Jacobs (2015a) for detailed discussions of this problem).

The different approaches, foci and interests can give a somewhat scattered and fragmentary picture of what EMI is, can, or should be. The fragmentation can, for instance, be seen in studies of pedagogical development, which have tended to highlight certain aspects. One concern has been to develop EMI classroom teaching methodology, typically arguing for the need for teachers to broaden their didactic toolbox (Ball and Lindsay 2013) and to use more active or student-centred methodologies (Cots 2013, Mehisto, Marsh and Frigols 2008, Wilkinson 2013). Another central area has been content teachers' language proficiency (see for example, Dimova 2017, Dimova and Kling 2015, Drljača Margić and Vodopija-Krstanović 2018, Klaassen and De Graff 2001, Kling and Stæhr 2011, and Valcke and Pávon 2015). A recent study by O'Dowd (2018) indicates that language proficiency has been the main component of many teacher training programmes or courses for EMI teachers in Europe. Important as these areas 
may be, they only address some of the aspects required for the development of effective teaching and learning in EMI contexts. Haines addresses this imbalance in foci when arguing that 'we need to consider the educational environment as a whole; and this involves thinking beyond language proficiency while still recognizing that the language proficiency of these content teachers is an important issue deserving of professional attention' (2017: 41). At some basic level, Haines's work highlights that the shared concern for all stakeholders involved in teaching and learning is to find 'ways of promoting effective learning' (Wilkinson 2018: 612).

Haines (2017) also refers to constructive alignment as a framework that can inform EMI when focusing on student learning. One of the main concerns according to Haines is 'how we can be sure, once these learning outcomes [for EMI courses] have been described, that the learning actually does occur' (2017: 42, my square brackets). The training and certification of staff is thus important, but it is also important to follow what such certification leads to and what types of teaching and learning environments students meet. On the basis of a few pilot cases, Haines (2017: 53) identifies in some contexts a need to more clearly establish what the expectations on products used for assessment are and for more clearly aligning student products with learning outcomes. He concludes that more studies of a similar type, but from different settings, are needed to further understand the challenges of both students and teachers.

Another challenge that still seems to be quite persistent in the field is the issue of content and language teacher collaboration, despite a fairly extensive body of research on the topic (for example, Gustafsson et al. 2011, Jacobs 2005, 2007, 2010, Leibowitz et al. 2011, Marshall et al. 2011, Murray and Nallaya 2016, Paxton 2011, Zappa-Hollman 2018). In many university settings, such collaboration is still difficult to achieve, and according to Schmidt-Unterberger there is an 'urgent need for increased collaboration between discipline experts and language specialists' (2018: 535). In addition, recent research has also shown the challenges of making the collaboration fruitful (Murray and Nallaya 2016). Consequently, there still seems to be a need for studies that can exemplify what such collaboration may entail and what the contribution of content and language specialists may be in different contexts. Haines' (2017) research also seems to suggest that the potential of such collaboration needs to be displayed.

The present study presents a particular type of content and language teacher collaboration in which the language teacher takes the role of supporting the improvement of students' disciplinary texts by unpacking disciplinary genre conventions and assisting in the alignment of the writing assignment to scaffold student learning as well as disciplinary writing. It hence provides an example of a kind of collaboration that can have substantial effects on the texts that the students produce in the course and on the students' learning, for instance regarding disciplinary genre conventions. The study stems from an initial survey of writing assignments on an MSc programme for Electric Power Engineering, which led to the identification of assignments on one course that seemed particularly challenging to students and which the course manager was not content with. The main aim of the study is to account for this writing assignment, to unpack the challenges that the students' faced and to describe how students and staff experienced the redesign. The focus is thus on the redesign, and the study exemplifies a type of content and communication specialist collaboration that can be fruitful in EMI contexts.

\section{Introducing the context and the assignment}

The students on the programme are a mix of students with a Swedish or non-Swedish educational background. The non-Swedish students primarily come from Asia and Europe. ${ }^{1}$ Because students come from different backgrounds, they bring different experiences of disciplinary writing. For instance, students who have also done their bachelor's years, at the university where this master's programme is given, have typically experienced several embedded communication modules and have extensive experience of writing collaboratively. Here, the influence of educational background has not been studied specifically, but it is a

\footnotetext{
${ }^{1}$ In terms of language requirements, Swedish students and students from the Nordic countries are required to have taken courses up to a specific level in Swedish upper secondary education (or equivalent). Students from outside of Sweden and the Nordic countries are required to have an IELTS score of 6.5 or a TOEFL score of 90 (Internet-based) or 575 (paper-based).
} 
contextual feature that is important to be aware of and that characterises this particular EMI context.

The writing assignment addressed in this study is given in a course at the end of the first year of the two-year master's programme. The assignment, including the writing, is done collaboratively in groups of four or five students. The students choose who to collaborate with, which means that some groups are very homogenous in terms of first language and educational background, while some groups are more mixed. The aim of the assignment is for the students to learn to design and operate different circuit models by developing such designs in a simulation software. From the perspective of the course manager, the main problem of the assignment before the redesign was that the students did not produce the types of texts expected and that it was difficult to distinguish between high- and low-quality texts with the criteria available for grading.

The lab work is divided into three tasks, and the assignment is hence structured in a way that may tempt students to divide the paper up task by task, but the teacher wants students to avoid using such a structure and instead wants them to write the text like a traditional paper with a theory and results section (but ideally with more descriptive headings). The theory section should only include theory about the circuits which are designed.

The involvement of language and communication specialists on the EMI master's programmes at the university varies between programmes. The involvement depends on the need seen by the programme manager, who may contract staff from the language and communication unit to scaffold a certain need. The direct involvement of writing and communication teachers on the MSc programme investigated has previously been limited to one course in the final year, which involves a report writing assignment supported by communication faculty in an integrated course design. However, a few of the teachers on the programme have taken a staff development course on teaching in English with a special focus on assignment design and constructive alignment. This experience has had some impact on the programme design. Students have various short writing assignments in the first year, but none of those courses has a specific writing focus.

\section{Theoretical frameworks}

When investigating a writing assignment in an EMI context, different theoretical lenses and perspectives can be used, for example constructive alignment (Biggs and Tang 2011), genre analysis (Devitt, Reiff and Bawarshi 2004, Johns et al. 2006), academic literacies (Lea and Street 1998, 2006, Lillis and Scott 2007, Lillis et al. 2015), integrating content and language (ICL) (Gustafsson and Jacobs 2013), and Dafouz and Smit's (2016) conceptual ROADMAPPING framework. ${ }^{2}$ All of these frameworks are relevant, but here ROAD-MAPPING is used as the umbrella framework, partly because it has been developed for studies of EMI contexts, but also because it allows for studies of specific aspects while still reminding us that these dimensions sit in a larger framework and may affect other dimensions in this framework. In addition, some of the other theoretical perspectives listed above are subsumed in the ROADMAPPING dimensions chosen as the foci of this study.

The ROAD-MAPPING framework was developed with the aim of providing a holistic and theoretically sound framework to be used for research on EMI in a broad sense (Dafouz and Smit 2016). The framework contains six different components or dimensions: Roles of English (RO), Academic Disciplines (AD), (Language) Management (M), Agents ( $A)$, Practices and Procedures (PP), and Internationalization and Glocalization (ING) (together forming the acronym ROAD-MAPPING). The framework is designed to be used for studies along all dimensions of a single context, or for studies of a single or a few dimensions across several sites, but also allows for studies of a few dimensions in a particular setting.

The three components that are relevant for the present study are Academic Disciplines (AD), Practices and Procedures (PP) and Agents (A). The AD and PP dimensions are considered

2 The issue of different entry points to the field is discussed in more detail in Gustafsson and Jacobs (2013). 
particularly important for this study as a result of the needs analysis of the assignment and the course design (see the section entitled 'The needs analysis stage: analysing the assignment and understanding the assignment context' below). The Agents (A) dimension is of interest because it captures collaboration between content and communication teachers. This dimension can obviously involve many different actors, but here the dimension is limited to content and communication teachers.

$A D$ involves academic socialisation and the learning and understanding of disciplinary practices (Dafouz and Smit 2016). The dimension therefore subsumes many issues highlighted within the academic literacies framework (Lea and Street 1998, 2006, Lillis et al. 2015: 15, Lillis and Scott 2007), for instance the connection between writing and learning. AD also encompasses approaches to learning to write in a discipline, for instance genre analysis (Hyland 2007, Swales and Feak 2012, Tardy and Swales 2014). AD becomes relevant in the present study because it involves students' understanding of genre expectations in the field and how students manage to adapt to changing expectations. It also draws attention to issues of tacit and explicit knowledge and the difficulty some disciplinary experts may face when trying to explicate knowledge about writing in their fields (Blåsjö 2011, Elton 2010, Geisler 1994, Jacobs 2007). The $A D$ dimension hence caters for an analysis that involves genre knowledge as well as academic literacy.

Practices and Processes (PP) concern the types of teaching and learning activities that are found on a course, a programme, or across a university, including how activities are presented and sequenced. The focus is on processes involved in teaching and learning, and this dimension therefore spans one of the central issues of EMI and ICLHE, namely how language and content integration is organised. This dimension therefore becomes important when evaluating course designs and discussing how different teachers can contribute to the setting up of effective teaching and learning environments.

Since PP concerns the organisation of teaching and learning, it is linked to other approaches to improving and optimising student learning, such as constructive alignment. Constructive alignment (CA) is a model or approach to teaching and learning that emphasises the importance of aligning learning outcomes, learning activities and assessment (Biggs and Tang 2011). In the redesign of a writing assignment, the alignment may involve things such as expressing expectations and outcomes in a clear manner, designing activities that support students' chances of performing in line with the expectations and using genres that are appropriate for the assessment of the content to be learnt. CA also emphasises alignment across a curriculum to avoid courses being aligned internally but misaligned at programme level (Biggs and Tang 2011: 127).

Another framework that is relevant when working with the redesign of writing assignments in an engineering context is Paretti, McNair and Leydens' (2014) set of guidelines for the development of engineering communication assignments. These guidelines draw on findings from several theoretical frameworks, including constructive alignment, academic literacies and genre analysis. The framework contains six guidelines, four of which are relevant for the genre and the integrated context investigated in the present study:

- assignment design benefits from collaboration between engineering and communication teachers;

- communication should be established across a program and be embedded within engineering courses;

- effective feedback is crucial;

- rubrics should be used to highlight what is important and highly valued in an assignment.

As can be seen, the guidelines concern different aspects and levels of a writing assignment and serve as a useful lens on teaching and learning contexts that require further development. The guidelines have however not been developed specifically for EMI contexts, and as a consequence, ROAD-MAPPING is taken as the primary point of departure as it reminds us that alignment that is done in an EMI context may be influenced by or influence dimensions not 
necessarily present in a non-EMI context. For instance, writing challenges discovered in a course or on a programme may influence language management (M) issues, such as requests for pre- or in-sessional courses on writing in English.

\section{Method and data analysis}

The present study involves the assessment and redesign of task descriptions and criteria as well as analyses of student texts and interviews with students and the course manager. The main data consist of:

- $\quad$ observations and documentation of the redesign of task descriptions and criteria;

- $\quad$ student texts from both before and after the redesign (10 groups, 2015 and 9 groups, 2016) for one of the writing assignments, including three drafts and feedback on drafts;

- 6 post-redesign student interviews (2016) (between 34 and 47 minutes long);

- 1 post-redesign teacher interview after the course finished (2016) (60 minutes).

All students from the 2016 group were invited to participate in interviews after the course, but only six students agreed to participate. One of the reasons for this may have been that the interviews happened just before, or after, final exams at the end of term. The strategy was chosen because it seemed important that students had completed the assignments before the interview was held. Invitations to interviews were sent out a few weeks before the end of the course.

The study is an intervention study in the sense that the author was involved in the redesign of the task descriptions and criteria and also by giving a one-hour lecture on data commentary. There were also conversations between the content teacher and the communication teacher before, and to some extent, during the course. The communication teacher (and author) was however not involved in any teaching activities beyond the data commentary lecture.

In the redesign process, course documents in the form of task descriptions were compared with the teacher's description of what the students were supposed to do and what the students were to achieve. The documents were then revised with the aim of explicating and clarifying features that seemed to be missing or that were not clear.

Student and teacher interviews were recorded and then transcribed verbatim. Students who spoke Swedish were given the choice of doing the interview in Swedish or English. Interviews conducted in Swedish were transcribed verbatim. Passages used in this article were translated into English. All participants gave their consent to the interviews being recorded and the interviews being used for research purposes. The interviews were analysed by means of open coding as presented by Miles, Huberman and Saldaña (2014). The student interviews were primarily used to find out how the students experienced the assignment after the redesign and what they felt they learnt. In the initial phase of the coding, words like 'learn', 'understand', 'understanding' and 'know' were marked to find sections of the interviews that seemed to address these issues. These sections were then analysed more carefully to identify themes connected with students' perceptions of learning.

Another aspect investigated in the interviews was what the students found challenging. To identify such passages, words like 'challenge', 'difficult', 'hard', 'concern', 'wrong' and 'not clear' were marked and then also analysed in more detail.

In the text, quotations are identified by interview number. Quotations have been made more readable by using ellipsis in square brackets to indicate words or phrases that were omitted from the quotations (for instance, because interviewees sought to find appropriate English terms). Unbracketed ellipsis denotes pauses in the informants' speech. When students used the name of the course instructor, the name has been anonymised and replaced by [name of the teacher] in the examples. 


\section{Results}

The redesign of the course consisted of three stages: the needs analysis stage; the implementation and outcome stage; and the follow-up interview stage.

\section{The needs analysis stage: analysing the assignment and understanding the assignment context}

Pedagogically, the first step was to understand what would be valued in the course and the discipline and what the teacher expected from the students in terms of learning and performance. This inventory involved conversations with the course manager and analyses of central course documents, such as student texts from the previous year (2015), task descriptions and criteria. The analyses indicated that: 1) the lab exercises worked well and the main challenge was the writing; 2) the teacher wanted the students to learn more about scientific article formats in the discipline (the teacher referred to expectations on papers published by the Institute of Electrical and Electronics Engineers (IEEE)); 3) the selection of content was important; 4) the presentation of results, primarily through effective graphs and data commentaries (in-text comments on figures and tables), was also important. Careful analyses of student texts from 2015 showed that it was difficult for students to reach these goals. In terms of writing needs and improving the texts produced, students primarily had to improve the organisation and structure of the texts, be more selective to focus on the most relevant points - particularly in the theory and results sections, and also display data more effectively in graphs and figures.

The text analyses showed that there were language proficiency mistakes in the texts, but in terms of improving the texts and the students' learning, issues related to grammar and vocabulary were considered comparatively small. This is not to suggest that language proficiency is an unimportant aspect and a challenge for many students, but, in this particular course context, the measures that were considered having the greatest potential for improving the texts were related to the AD and PP dimensions of the ROAD-MAPPING framework. What also needs to be remembered is that the writing in the course is done collaboratively, and it is possible that students as a group were able to handle the language quite well, potentially concealing individual weaknesses.

The inventory also involved investigating how the expectations had been communicated in task descriptions and assessment criteria and how students were expected to transfer laboratory work into text. Several of these expectations were not clearly expressed, and an important aspect of the redesign was therefore to clarify what was valued in the assignment. This part of the study therefore involved aligning course documentation with expected outcomes as well as to clarify genre expectations.

The task description was developed to include a more detailed introduction, partly because the original description focused very strongly on lab activities. The new version of the description outlined the connection between the assignment and the intended learning outcomes of the course and gave an overview of the written assignment and its main sections. Another important revision concerned comments on how to account for lab activities in text. The original task description had a fairly strong focus on the actual activities. For instance, the students were often instructed to 'observe' activities, but it was not explicitly stated if, or how, these observations were to be represented in the text. Only observing events and outcomes in the lab is obviously not enough. These observations have to be described, explained and discussed in the text. The task description was therefore rewritten to try to address the transfer from lab activity to text. This type of focus highlights the importance of not only considering text but also practices connected with text (Lillis et al. 2015: 15; c.f. also the PP dimension in the ROADMAPPING framework) and that such concerns can be raised in content and communication teacher collaboration.

Several parts of the assessment rubric were also rewritten. The revised rubric is shown in Appendix 1, and major changes were: 
- The original rubric contained three criteria categories, whereas the revised one contains five categories. The additions were separate categories for structure/flow and discussion.

- The new rubric has a stronger focus on selection of content. The importance of selection is primarily highlighted in the theory and results categories.

- The importance of data commentary is highlighted, both in the results category and in the language and mechanics category.

In summary, the needs analysis pointed to the need for changes affecting the academic discourse (AD) dimension in terms of clarifying and unpacking disciplinary conventions. The analysis also indicated that certain practices and processes (PP) could clearly signal the importance of particular disciplinary expectations, such as visuals and data commentary. The needs analysis also indicated that students needed to invest more heavily in certain practices, such as deciding what is central and should, therefore, go into the final version. The collaboration between the content and the communication teachers (Agents) made it possible to pinpoint what could be improved and how this could be communicated to students.

\section{The implementation and outcome stage: the effects of the redesign}

The evaluation of the effect of the measures implemented is based on text analyses, student interviews and an interview with the course manager. The text analyses were not detailed but looked at the number of pages, headings, the overall structure of the paper and references to figures and tables. The main aim of the text analyses was to see whether or not changes in practices and processes made the students improve their texts in terms of complying with disciplinary genre expectations. The analysis is based on comparisons between texts from before and after the redesign (2015 vs. 2016) along the features identified as problematic.

\section{Comparisons of texts and feedback}

One of the initial concerns from the course manager was that the texts were too long, and in the needs analysis, this was interpreted to mean that the students were not selective enough when writing their texts. The issue of selection was also considered an important aspect of disciplinary communication. The analysis shows that the final drafts of the papers from 2015 were between 19 and 27 pages long, while the final drafts from 2016 were between 12 and 15 pages. The number of pages obviously has clear limitations as an indicator of change, but it still indicates that the format of the papers is different and perhaps also that students have been able to be more selective in their presentation. However, the difference between the drafts from the two years did not fully show until the third and final draft. For the first draft, the great majority of texts from both years were between 10 and 15 pages long. The initial response to the task description and the criteria thus seemed to be similar, but the processes from the first draft to the second, and then the final one, generated different end results.

One of the major differences between the two years concerned feedback procedures. In 2016, the course manager used the rubric in the feedback process in order to indicate what level the text had reached following the criteria (outstanding (100\%), good $(50 \%)$ or inadequate). The rubric also came with an additional overall comment to clarify the assessment. The rubric was thus used as a formative assessment tool.

In addition, the teacher made more comments in the running text on the drafts. For instance, the teacher clearly gave more comments on the second draft in 2016 than in 2015 (on average 8 comments per text in 2015 versus 26 in 2016). Merely counting comments obviously gives very little information about the types of comments given, but it nevertheless indicates a change of practices between the two years. The increased and more detailed level of feedback found also aligns with the teacher's perception, who after the course stated that 'I was more specific $[\ldots]$ on the feedback we made $[\ldots]$ this year'.

One of the changes that is most apparent in the student drafts is that the lab tasks were not used as the main structuring principle of the theory and results sections. The texts instead had to be organised on the basis of the theory and results that were relevant for the entire assignment. For example, instead of calling the headings in the results section 'Task 1' with the subsections 'Simulation' and 'Data analysis', the results sections of the 2016 texts had more 
descriptive headings, such as 'Design and implementation of a diode snubber'. These differences indicate that changes in instruction and feedback made it clearer to students that they could not simply present their results task by task and that the students were able to adopt these genre expectations in their own writing.

The tendency of students to structure their early drafts task by task may also reflect that they were influenced by previous tasks and requirements on the programme. An overview of assignments handed in during the first year showed that students were often expected to present assignments as answers to a set of questions. From a student perspective, it may therefore seem logical to organise the text task by task, as this structure was familiar and had been accepted in previous assignments. These findings seem to align with claims within constructive alignment emphasising the importance of aligning at programme level (Biggs and Tang 2011), and also with Lea and Street's (1998: 161) findings of course switching, meaning that requirements shift between courses, but teachers do not necessarily recognise these differences or do not clearly communicate them to students. Consequently, students have to figure out what the expectations of a particular course are.

A final qualitative difference between the texts from 2015 and 2016 was that figures and tables were commented on more carefully in the 2016 texts. In the texts from 2015, many figures were not properly introduced and results were not commented on. Some of the reasons why students were more careful in their data commentaries after the redesign were probably that a lecture on data commentary was introduced in the course, that the value and importance of data commentaries were made more explicit in the rubric, and that the teacher could use the rubric to highlight the importance of data commentaries when giving feedback. All in all, these measures seem to have contributed to the students' improved use of an important genre characteristic.

\section{The follow-up interview stage}

When performing an assignment redesign, like the one described here, it is important to capture the student perception of the assignment and the practices associated with it. The student interviews indicate that the students learnt both disciplinary writing and content (so, aspects of the $A D$ dimension) and that procedures and practices involving feedback were essential for this learning to take place.

\section{Students' perceptions of learning from the assignment}

First of all, it was clear to students that the purpose of the exercise was to learn to apply diode snubbers and to write a report (the students tend to use the term 'technical report' to refer to various types of texts written to present project work). The students felt that the assignment served these purposes quite well as they learnt both circuit designs and discipline-specific writing, as shown by the following comments:

When it comes to technical part, I would say, it was expected [...] we did learn [...] a bit more about the snubber in the first report, we read about the snubber, how to design it [...] but in my opinion, the best part was to learn how to write a report [...] the format, we learned about using Matlab to produce graphs, really sharp and, you know, nice looking graphs [1006]

Interviewer: What was the purpose of those exercises the way you understood it or understood them?

Student: I think that it has like two main goals like first was [...] getting better like [...] to the subject that we studied like [...] the snubbers or like all the parts that we did in the course to get a better understanding of this and the second one was just this lots of feedback so we really learnt how to like write a good report and [...] to improve $[\ldots]$ our report writing [1004] 
All students made similar types of comments, with some students emphasising the perceived focus on and learning of report writing. ${ }^{3}$

The learning of new aspects of disciplinary writing was connected with demands on writing, as the demands on writing seemed to be higher in this course than in previous courses on the programme. The assignment was perceived to be more open ended, and the openness put higher demands on selecting material to include in the text and also partly on distributing the material properly, as exemplified by the following comment:

What did I learn? [...] how to structure it [the report] I mean how you have a good introduction what kind of previous knowledge you should mention and that [...] you should keep it short as possible and [...] still you should mention all the important parts [...] that I learnt [1001]

The open-ended nature of the task meant that the students had to negotiate both what to include ('keep it short') and how to organise the text ('how to structure it'). There was thus an element of complexity that involved both the handling of fairly large amounts data and the selection and presentation of the data that were most relevant.

Several students also highlighted the value of learning more specific ways of presenting data, both visually and through appropriate data commentary:

Interviewer: What did you learn about writing in this course?

Student: Well, it was probably to comment on data, to present your findings [...] more that than report structure.

Interviewer: And this was new to you, I mean, after all you have studied and written your bachelor thesis

Student: Yes, it has not been this clear so that you have been on top of things but after this course you know how to present a figure, from how to introduce it until you have left it. [1005]

Yeah of course we have done this [written data commentaries] before but I mean when we did it before everyone [...] assumed that that we know how it works [...] and no one ever complained on stuff like this. [1002]

The students had written data commentaries before, but the writing in this course made requirements of this aspect of disciplinary writing more explicit. Conversations with the content teacher revealed that changes in the precision of the data are significant not only from the perspective of how data is presented, but also from the perspective of disciplinary understanding. For instance, when displaying overvoltage and stray inductance, students may choose very different levels of detail by zooming in differently on the curves displaying these phenomena, and the zoom chosen indicates whether or not the students have understood the significance of the measurement. Such aspects of displaying data are difficult to identify without a content teacher involved in the teaching of disciplinary writing.

Overall, the students' and teachers' perceptions were that the writing was challenging to begin with but that it eventually became more effective. The teacher argued that the products had improved: 'if you compare the final reports this year and last year you're going to see a significant improvement'. At the same time, the teacher had some difficulties substantiating what the improvement consisted of, which is in line with findings from other studies saying that content lecturers may have difficulties to clearly explicate what makes a text good and what is

${ }^{3}$ There was a tendency among the interviewees to talk a bit more about the writing than about the content, possibly because the interviewer had been involved in a lecture on data commentary and the students hence knew that he was from the division of language and communication. 
valued in writing in the discipline (for example, Fischer 2015, Geisler 1994, Gimenez and Thomas 2015, Ingle and Yakovchuk 2015, Jacobs 2007, 2015b).

\section{The importance of feedback}

In the process of understanding the demands of the genre, the revised task description and criteria were perceived as useful, but it is also quite clear that feedback from the teacher was a highly important practise in the process:

You didn't really know what was wrong but then [name of the teacher] was there a few times so it was not really a big problem [...] I think it's very good because you can talk [...] through the topics with [name of the teacher] very easily. [1002]

The feedback was needed as a way of negotiating drafts and choices made. This negotiation could also involve explication of the rubric:

Well, it is not so easy to follow one of those [rubrics] because I think that most of the pass-grades it is expressed that it has to be sufficient and it is hard to know [...] that is [...] but at least it lets you know what you should focus on. [1005]

The rubric seems to have given valuable guidance, but students also had to negotiate it with the teacher in order to interpret and understand genre expectations.

The feedback seemed to work in terms of negotiations around the students' text. The text is however only one aspect of a genre. The text is also influenced by the context in which it is produced, and this aspect the content lecturer was less aware of. For instance, he kept coming back to the requirements of publishing for a journal:

It actually doesn't take a lot of effort to get the page number down it just takes [...] a little bit of creativity how to present data and that creativity is often required when you want to write an article or [...] if you want to submit an article to a IEEE journal everything that goes above eight [pages] is rejected immediately. [2001]

The teacher primarily seemed to see genre as a format and paid less attention to the fact that the students were producing this genre in different circumstances than researchers writing for publication and that these circumstances may affect the writing. Writing a text that resembles a particular genre is not simply a matter of following a format and being a bit creative. The production is very much dependent on contextual factors as well. The consequence of focusing on the format of the genre may be that the genuine ambition of changing the writing in the course is partly limited, as the complexity of the assignment and its context is not fully acknowledged (Lillis and Scott 2007: 6). Here, the contextual perspective and its potential influence on the text were brought in by the communication teacher, indicating that these are possible contributions of communication lecturers in redesign processes.

\section{Discussion and conclusion}

The initial needs analysis of this intervention study showed that the engineering teacher was not content with what the students produced and lamented the lack of criteria that could differentiate between student submissions. These concerns initiated a redesign process in which the rubric, the task description and, to some extent, the feedback procedures were revised. Student texts produced before and after the redesign were then compared, and students and the engineering teacher were interviewed about their perceptions.

The students' main challenge was to understand the genre expectations of the assignment. One particularly important part of the redesign was therefore to unpack and make explicit aspects of writing that were valued in the discipline and in the course (c.f. the AD dimension of the ROAD-MAPPING framework). An important step in clarifying the genre expectations was to improve instruction via course documents. The issues were addressed through a revised project description, the development of more precise assessment criteria in the assignment 
rubric, and more input on particular features of the genre (particularly data commentary). These measures generated better end products, and the students found that they learnt the disciplinary content as well as new aspects of disciplinary writing. The assignment particularly challenged the students to structure their texts differently, to be selective and to work on graphing and data commentary.

Another important finding related to genre analysis is that the engineering teacher on the course partly seemed to underestimate the difference between the situations in which a student report and a scientific research paper are produced. Some of the problems thus seemed to reside in focusing too much on genre as a format. The study therefore underlines the importance of considering text as well as context when working on disciplinary writing (see, for example, Jacobs 2015b, Paretti, McNair and Leydens 2014). Often, circumstances are different and these circumstances may influence literacy practices.

The changes in instruction helped students understand course and genre requirements better, but the interviews clearly showed that feedback practices were still essential for the students' understanding of what is important (Paretti, McNair and Leydens 2014). The assignment was perceived to be somewhat more open-ended than many of the tasks that the students had been given previously on the programme and the possibility to negotiate expectations via feedback on drafts was therefore very important.

Next, the results of this study align with studies that point to the value of applying a programme approach to writing and assessment (see, for example, Paretti, McNair and Leydens 2014, Patton 2008, Reave 2004, Wagner, Hilger and Flash 2014). For example, both interviews and text analyses indicated that experience from previous assignments influenced students' approach to writing. At least some students may have been affected by the similarity between previous task descriptions and the one for the present assignment as well as what they had been asked to produce previously on the programme (providing answers to questions). Teachers and instructors would, therefore, probably benefit from being able to refer to previous assignments that the students have done. In that way, they could contrast the expectations of those assignments and genres with the expectations of the genre the students are expected to use in the course at hand. However, both the influence of previous assignments on student performance and the genre challenges of students in particular EMI contexts are issues that would merit further research.

This study suggests that a programme approach to writing is less likely to be successful if it does not involve both content and communication staff as agents in the process. Examples from course contexts similar to the one studied here have shown that content teachers can be encouraged, in such collaborative settings, to produce more effective writing assignments (Gustafsson and Boström 2012: 384, Bylander and Gustafsson, in press). Content faculty typically sit on considerable expertise of writing in their discipline, but within the fields of academic literacies and integrating content and language, it is quite well-known that it may be difficult to unpack this expertise so that it becomes accessible to students (see, for example, Fischer 2015, Geisler 1994, Gimenez and Thomas 2015, Ingle and Yakovchuk 2015, Jacobs 2007, 2015b, Paretti, McNair and Leydens 2014). This study exemplifies what such unpacking may consist of: clarifying task descriptions so that what is taken for granted by faculty is made explicit to students, highlighting contextual differences between writing for publication and writing in an educational context, and taking previous writing assignments on the programme into account. It has also been shown how engineering and communication faculty can collaborate in such a process. For example, engineering faculty could explain the importance of data commentary and communication faculty could highlight selection of content as an important aspect of the genre that had not been made explicit in previous instructions and rubrics. Instead of taking for granted that carefully selecting content is something that the students would do, the rubric, task description and feedback were aligned to highlight selection as an important disciplinary literacy practice (Jacobs 2015b). This type of collaboration therefore requires communication teachers that are comfortable with genre analysis and assignment design, as well as content and communication teachers who are willing to negotiate key elements and genre expectations. 
The collaboration and mechanisms involved in the collaboration exemplified here is, in many ways, similar to constructive alignment initiatives in any type of teaching and learning situation. It is therefore not so obvious how this EMI context is different from other teaching and learning contexts, but the ROAD-MAPPING framework reminds about the potential influence on and from other dimensions. The language component, in the form of language proficiency issues such as vocabulary and grammar, is present when students write in English, and even though it is not considered the key component for the students' improvement of the assignment studied here, it will be a component that teachers will have to take into consideration when analysing the needs of a particular course. In addition, challenges connected with writing and language often go into a general category of 'language problems' for content teachers. Here, the teacher collaboration could generate a more detailed analysis of genre conventions and disciplinary expectations, which made both the content and the communication teacher active agents in the analysis of the assignment and helped them clarify what may be particularly important to focus on if the texts were to improve. The study therefore exemplifies a type of discussion that is necessary in many EMI contexts and that brings the discussion closer to considering 'the educational environment as a whole' (Haines 2017: 41).

The sample of students interviewed in this study is clearly limited and there are challenges that may not have been mentioned or appropriately highlighted in the interviews. Nevertheless, the example presented is not unique, and it therefore gives insights into the challenges of writing and learning in higher education EMI contexts. In particular, it exemplifies how content and communication faculty can collaborate to unpack the challenges of writing assignments that are used for assessment purposes. The study also indicates the types of challenges that students may face if programmes do not take a clear programme approach to writing and content faculty is unaware of the type of writing that is done on the programme. From a programme and student perspective, it is therefore important that the forms of activities are adjusted to meet the requirements of the discipline, hence requiring 'versatile solutions of the constructive alignment puzzle in designing the environment' (Gustafsson 2011: 101).

\section{Acknowledgements}

The author would like to thank the editors and the anonymous reviewers for their constructive comments. This work was supported by The Swedish Research Council (grant number 20132373).

\section{Declaration of interest}

No potential conflict of interest was reported by the authors. 


\section{References}

Aguilar, M., and Muñoz, C. (2014) 'The Effect of Proficiency on CLIL Benefits in Engineering Students in Spain'. International Journal of Applied Linguistics 24 (1), 1-18

Airey, J. (2010) 'The Ability of Students to Explain Science Concepts in Two Languages'. Hermes-Journal of Language and Communication Studies 45, 35-49

Ball, P., and Lindsay, D. (2013) 'Language Demands and Support for English-Medium Instruction in Tertiary Education Learning From a Specific Context'. In English-Medium Instruction at Universities: Global Challenges. ed. by Doiz, A., Lasagabaster, D., and Sierra, J. M. Bristol: Multilingual Matters, 44-61

Biggs, J., and Tang, C. (2011) Teaching for Quality Learning at University: What the Student Does. 4th edn. Maidenhead: Open University Press

Blåsjö, M. (2011) 'From Percentage to Prediction: University Students Meeting a Parallel Language of Visuals and Numerals'. Ibérica 22, 123-140

Bylander, J., and Gustafsson, M. (in press) 'Improving Understanding and Written Communication'. in Quantum Engineering: The Design of an Experimental Lab Report Assignment

Cots, J. M. (2013) 'Introducing English-Medium Instruction at the University of Lleida, Spain: Intervention, Beliefs and Practices'. in English-Medium Instruction at Universities: Global Challenges. ed. by Doiz, A., Lasagabaster, D., and Sierra, J. M. Bristol: Multilingual Matters, 106-128

Dafouz, E., and Smit, U. (2016) 'Towards a Dynamic Conceptual Framework for EnglishMedium Education in Multilingual University Settings'. Applied Linguistics 37 (3), 397 415

Devitt, A. J., Reiff, M. J., and Bawarshi, A. S. (2004) Scenes of Writing: Strategies for Composing with Genres. New York: Pearson Longman

Dimova, S. (2017) 'Life after Oral English Certification: The Consequences of the Test of Oral English Proficiency for Academic Staff for EMI Lecturers'. English for Specific Purposes 46, 45-58

Dimova, S., and Kling, J. (2015) 'Lecturers' English Proficiency and University Language Policies for Quality Assurance'. in Integrating Content and Language in Higher Education. From Theory to Practice. Selected Papers from the 2013 ICLHE Conference. ed. by Wilkinson, R., and Walsh, M.L. Frankfurt am Main: Peter Lang, 6174

Doiz, A., Lasagabaster, D., and Sierra, J. M. (2013) 'Future Challenges for English-Medium Instruction at the Tertiary Level'. in English-Medium Instruction at Universities: Global Challenges. ed. by Doiz, A., Lasagabaster, D., and Sierra, J. M. Bristol: Multilingual Matters, 213-221

Drljača Margić, B., and Vodopija-Krstanović, I. (2018) 'Language Development for EnglishMedium Instruction: Teachers' Perceptions, Reflections and Learning'. Journal of English for Academic Purposes 35, 31-41

Elton, L. (2010) 'Academic Writing and Tacit Knowledge'. Teaching in Higher Education 15 (2), 151-160 
Fischer, A. (2015) "'Hidden Features" and "Overt Instruction" in Academic Literacy Practices: A Case Study in Engineering'. in Working With Academic Literacies: Case Studies Towards Transformative Practice. ed. by Lillis, T., Harrington, K., Lea, M., and Mitchell, S. Fort Collins, CO: The WAC Clearinghouse and Parlor Press, 75-85

Geisler, C. (1994) 'Literacy and Expertise in the Academy'. Language and Learning Across the Disciplines 1, 35-57

Gimenez, J., and Thomas, P. (2015) 'A Framework for Usable Pedagogy: Case Studies Towards Accessibility, Criticality and Visibility'. in Working With Academic Literacies: Case Studies Towards Transformative Practice. ed. by Lillis, T., Harrington, K., Lea, M., and Mitchell, S. Fort Collins, CO: The WAC Clearinghouse and Parlor Press, 2944

Gustafsson, M. (2011) 'Academic Literacies Approaches for Facilitating Language for Specific Purposes'. Ibérica 22, 101-122

Gustafsson, M., and Broström, T. (2012) 'Multi-Disciplinary, Multi-Lingual Engineering Education Writing Development: A Writing Programme Perspective'. in Writing Programs Worldwide: Profiles of Academic Writing in Many Places. Perspectives on Writing. ed. by Thaiss, C, Bräuer, G., Carlino, P., Ganobcsik-Williams, L., and Sinha, A. Fort Collins, CO: The WAC Clearinghouse and Parlor Press, 377-388

Gustafsson, M., Eriksson, A., Räisänen, C., Stenberg, A.-C., Jacobs, C., Wright, J., WyrleyBirch, B., and Winberg, C. (2011) 'Collaborating for Content and Language Integrated Learning: The Situated Character of Faculty Collaboration and Student Learning'. Across the Disciplines [online] 8 (3). available from <http://wac.colostate.edu/atd/clil/gustafssonetal.cfm> [12 September 2018]

Gustafsson, M., and Jacobs, C. (2013) 'Editorial: Student Learning and ICLHE-Frameworks and Contexts'. Journal of Academic Writing 3 (1), ii-xii

Haines, K. (2017) 'Purposeful Interaction and the Professional Development of Content Teachers: Observations of Small-Group Teaching and Learning in the International Classroom'. in Integrating Content and Language in Higher Education. Perspectives on Professional Practice. ed. by Valcke, J., and Wilkinson, R. Frankfurt am Main: Peter Lang, 39-58

Hyland, K. (2007) 'Genre Pedagogy: Language, Literacy and L2 Writing Instruction'. Journal of Second Language Writing 16, 148-164

Ingle, J., and Yakovchuk, N. (2015) 'Writing Development, Co-Teaching and Academic Literacies: Exploring the Connections'. in Working With Academic Literacies: Case Studies Towards Transformative Practice. ed. by Lillis, T., Harrington, K., Lea, M., and Mitchell, S. Fort Collins, CO: The WAC Clearinghouse and Parlor Press, 143-154

Jacobs, C. (2005) 'On Being an Insider on the Outside: New Spaces for Integrating Academic Literacies'. Teaching in Higher Education 10 (4), 475-487

Jacobs, C. (2007) 'Towards a Critical Understanding of the Teaching of Discipline-Specific Academic Literacies: Making the Tacit Explicit'. (Kenton Special Issue). Journal of Education 41, 59-81

Jacobs, C. (2010) 'Collaboration as Pedagogy: Consequences and Implications for Partnerships Between Communication and Disciplinary Specialists'. Southern African Linguistics and Applied Language Studies 28 (3), 227-237 
Jacobs, C. (2015a) 'Mapping the Terrains of ICLHE: A View from the South'. in Integrating Content and Language in Higher Education. From Theory to Practice. Selected Papers from the 2013 ICLHE Conference. ed. by Wilkinson, R. and Walsh, M. L. Frankfurt am Main: Peter Lang, 21-38

Jacobs, C. (2015b) 'Opening up the Curriculum: Moving from the Normative to the Transformative in Teachers' Understanding of Disciplinary Literacy Practices'. in Working With Academic Literacies: Case Studies Towards Transformative Practice. ed. by Lillis, T., Harrington, K., Lea, M., and Mitchell, S. Fort Collins, CO: The WAC Clearinghouse and Parlor Press, 131-141

Johns, A. M., Bawarshi, A. S., Coe, R. M., Hyland, K., Paltridge, B., Reiff, M. J., and Tardy, C. M. (2006) 'Crossing the Boundaries of Genre Studies: Commentaries by Experts'. Journal of Second Language Writing 15 (3), 234-249

Klaassen, R. G., and De Graaff, E. (2001) 'Facing Innovation: Preparing Lecturers for EnglishMedium Instruction in a Non-Native Context'. European Journal of Engineering Education 26 (3), 281-289

Kling, J., and Stæhr, L. S. (2011) 'Assessment and Assistance: Developing University Lecturers' Language Skills Through Certification Feedback'. in Policies, Principles, Practices: New Directions in Foreign Language Education in the Era of Educational Globalization. ed. by Cancino, R., Dam, L. and Jæger, K. Newcastle upon Tyne: Cambridge Scholars Press, 213-245

Knoch, U., Rouhshad, A., Oon, S. P., and Storch, N. (2015) 'What Happens to ESL Students' Writing after Three Years of Study at an English Medium University?'. Journal of Second Language Writing 28, 39-52

Lea, M. R., and Street, B. V. (1998) 'Student Writing in Higher Education: An Academic Literacies Approach'. Studies in Higher Education 23 (2), 157-172

Lea, M. R., and Street, B. V. (2006) 'The "Academic Literacies" Model: Theory and Applications'. Theory into Practice 45 (4), 368-377

Leibowitz, B., Bozalek, V., Carolissen, R., Nicholls, L., Rohleder, P., Smolders, T., and Swartz, L. (2011, October 8) 'Learning Together: Lessons from a Collaborative Curriculum Design Project'. Across the Disciplines [online] 8 (3). available from $<$ http://wac.colostate.edu/atd/clil/gustafssonetal.cfm> [12 September 2018]

Lillis, T., Harrington, K., Lea, M., and Mitchell. S. (eds). (2015) Working With Academic Literacies: Case Studies Towards Transformative Practice. Perspectives on Writing. Fort Collins, CO: The WAC Clearinghouse and Parlor Press

Lillis, T., and Scott, M. (2007) 'Defining Academic Literacies Research: Issues of Epistemology, Ideology and Strategy'. Journal of Applied Linguistics 4 (1), 5-32

Marshall, D., Conana, H., Maclons, R., Herbert, M., and Volkwyn, T. (2011) 'Learning as Accessing a Disciplinary Discourse: Integrating Academic Literacy into Introductory Physics through Collaborative Partnership'. Across the Disciplines [online] 8 (3). available from <http://wac.colostate.edu/atd/clil/gustafssonetal.cfm> [12 September 2018]

Mehisto, P., Marsh, D., and Frigols, M.J. (2008) Uncovering CLIL, Content and Language Integrated Learning, in Bilingual and Multilingual Education. Oxford: Macmillan Education

Miles, M. B., Huberman, A. M., and Saldaña, J. (2014) Qualitative Data Analysis: A Methods Sourcebook. 3rd edn. Thousand Oaks, CA: Sage 
Murray, N., and Nallaya, S. (2016) 'Embedding Academic Literacies in University Programme Curricula: A Case Study'. Studies in Higher Education 41 (7), 1296-1312

O'Dowd, R. (2018) 'The Training and Accreditation of Teachers for English Medium Instruction: An Overview of Practice in European Universities'. International Journal of Bilingual Education and Bilingualism 21 (5), 553-563

Paretti, M. C., McNair, L. D., and Leydens, J. A. (2014) 'Engineering Communication'. in Cambridge Handbook of Engineering Education Research. ed. by Johri, A. and Olds, B. New York: Cambridge University Press, 601-632

Patton, M. D. (2008) 'Beyond WI: Building an Integrated Communication Curriculum in One Department of Civil Engineering'. IEEE Transactions on Professional Communication 51 (3), 313-327

Paxton, M. (2011) 'Research and Development in an ICL Project: A Methodology for Understanding Meaning Making in Economics'. Across the Disciplines [online] 8 (3). available from <http://wac.colostate.edu/atd/clil/gustafssonetal.cfm> [12 September 2018]

Reave, L. (2004) 'Technical Communication Instruction in Engineering Schools: A Survey of Top-Ranked U.S. and Canadian Programs'. Journal of Business and Technical Communication 18 (4), 452-490

Schmidt-Unterberger, B. (2018) 'The English-Medium Paradigm: A Conceptualisation of English-Medium Teaching in Higher Education'. International Journal of Bilingual Education and Bilingualism 21 (5), 527-539

Smit, U., and Dafouz, E. (2012) 'Integrating Content and Language in Higher Education. An Introduction to English-Medium Policies, Conceptual Issues and Research Practices across Europe'. AlLA Review 25, 1-12

Swales, J. M., and Feak, C. B. (2012) Academic Writing for Graduate Students. Essential Tasks and Skills. 3rd edn. Ann Arbor, MI: University of Michigan Press

Tardy, C. M., and Swales, J. M. (2014) 'Genre Analysis'. in Pragmatics of Discourse. ed. by Schneider, K. P., and Barron, A. Berlin: Walter de Gruyter, 165-187

Valcke, J., and Pávon, V. (2015) 'A Comparative Study on the Use of Pronunciation Strategies for Highlighting Information in University Lectures'. in Integrating Content and Language in Higher Education. From Theory to Practice. Selected Papers from the 2013 ICLHE Conference. ed by Wilkinson, R., and Walsh, M.L. Frankfurt am Main: Peter Lang, 323-341

Wagner, H. E., Hilger, A., and Flash, P. (2014) 'Improving Writing Skills of Construction Management Undergraduates: Developing Tools for Empirical Analysis of Writing to Create Writing-Enriched Construction Management Curriculum'. International Journal of Construction Education and Research 10 (2), 111-125

Wilkinson, R. (2013) ‘English-Medium Instruction at a Dutch University: Challenges and Pitfalls'. in English-Medium Instruction at Universities. ed. by Doiz, A., Lasagabaster, D., and Sierra, J. M. Bristol: Multilingual Matters, 3-26

Wilkinson, R. (2018) 'Content and Language Integration at Universities? Collaborative Reflections'. International Journal of Bilingual Education and Bilingualism 21 (5), 607615 
Zappa-Hollman, S. (2018) 'Collaborations Between Language and Content University Instructors: Factors and Indicators of Positive Partnerships'. International Journal of Bilingual Education and Bilingualism 21 (5), 591-606 
Appendix 1: Grading criteria, 2016

\begin{tabular}{|c|c|c|c|}
\hline Criteria & Outstanding (100\%) & Good (50\%) & Inadequate/fail \\
\hline $\begin{array}{l}\text { Theory, } \\
\text { phenomena, } \\
\text { problems } \\
(20 \%)(4 \text { points) }\end{array}$ & $\begin{array}{l}\text { Theory that is essential in } \\
\text { relation to the simulations } \\
\text { carried out has been } \\
\text { selected and is presented. } \\
\text { Relevant phenomena, } \\
\text { processes/sequences and } \\
\text { problems are described in a } \\
\text { clear manner. }\end{array}$ & $\begin{array}{l}\text { A good theoretical } \\
\text { introduction is given, yet } \\
\text { some irrelevant parts are } \\
\text { added and/or some parts } \\
\text { are missing. }\end{array}$ & $\begin{array}{l}\text { Theoretical } \\
\text { background is } \\
\text { incomplete and does } \\
\text { not reflect the } \\
\text { problems addressed } \\
\text { in the simulations. }\end{array}$ \\
\hline $\begin{array}{l}\text { Results, data } \\
\text { commentary, } \\
\text { discussions } \\
\text { (50\%)(10 } \\
\text { points) }\end{array}$ & $\begin{array}{l}\text { The results presented are } \\
\text { correct and clearly } \\
\text { connected with the } \\
\text { theoretical part. Important } \\
\text { comments on limitations or } \\
\text { advantages of the methods } \\
\text { used are made. } \\
\text { The presentation of results } \\
\text { shows that data has been } \\
\text { carefully selected and } \\
\text { processed to make the } \\
\text { presentation easy to follow } \\
\text { and understand. Central } \\
\text { results presented in figures } \\
\text { and tables are highlighted, } \\
\text { and important comments } \\
\text { and explanations of figures } \\
\text { and tables are made. The } \\
\text { comments may concern } \\
\text { topics like circuit design, } \\
\text { problems and results. }\end{array}$ & $\begin{array}{l}\text { The results presented are } \\
\text { correct, and the results } \\
\text { are commented on. } \\
\text { Overall the presentation } \\
\text { of results is clear, but } \\
\text { results have not always } \\
\text { been processed to make } \\
\text { the presentation effective. } \\
\text { For example, some } \\
\text { figures or tables do not } \\
\text { visualise results in a clear } \\
\text { way. }\end{array}$ & $\begin{array}{l}\text { Some of the } \\
\text { presented data and } \\
\text { results are wrong } \\
\text { and do not reflect the } \\
\text { theoretical part. } \\
\text { Results are } \\
\text { presented but not } \\
\text { commented on } \\
\text { appropriately. It is } \\
\text { therefore difficult for } \\
\text { a reader to know } \\
\text { how to interpret } \\
\text { results or how the } \\
\text { authors have } \\
\text { interpreted results. } \\
\text { Results have not } \\
\text { been selected and } \\
\text { processed to make } \\
\text { the presentation } \\
\text { effective. }\end{array}$ \\
\hline $\begin{array}{l}\text { Conclusion } \\
\text { (10\%) (2 points) }\end{array}$ & $\begin{array}{l}\text { The findings from the } \\
\text { simulations are commented } \\
\text { on in a concluding section. } \\
\text { The comment clearly } \\
\text { shows what can be } \\
\text { concluded from the types of } \\
\text { simulations that have been } \\
\text { carried out. }\end{array}$ & $\begin{array}{l}\text { The findings from the } \\
\text { simulations are correctly } \\
\text { commented on in a } \\
\text { concluding section. }\end{array}$ & $\begin{array}{l}\text { The text lacks a } \\
\text { concluding } \\
\text { discussion section or } \\
\text { the concluding } \\
\text { comments are } \\
\text { incorrect or } \\
\text { irrelevant. }\end{array}$ \\
\hline $\begin{array}{l}\text { Report structure } \\
\text { and flow } \\
(10 \%)(2 \text { points) }\end{array}$ & $\begin{array}{l}\text { Chapters and sections are } \\
\text { appropriately introduced, } \\
\text { and it is easy for the reader } \\
\text { to follow the presentation } \\
\text { within as well as between } \\
\text { sections (so moving from } \\
\text { one section to the next). }\end{array}$ & $\begin{array}{l}\text { Overall the text is easy to } \\
\text { read, but in some } \\
\text { passages, shifts from one } \\
\text { topic to the next are } \\
\text { abrupt and new topics or } \\
\text { results appear without } \\
\text { being introduced. }\end{array}$ & $\begin{array}{l}\text { The content may be } \\
\text { appropriate, but it is } \\
\text { difficult to follow the } \\
\text { presentation } \\
\text { because sections or } \\
\text { topics are not } \\
\text { appropriately } \\
\text { introduced and } \\
\text { linked. }\end{array}$ \\
\hline $\begin{array}{l}\text { Language, } \\
\text { referencing and } \\
\text { mechanics } \\
(10 \%)(2 \text { points })\end{array}$ & $\begin{array}{l}\text { Language is clear and } \\
\text { accurate. The reader can } \\
\text { easily understand the text }\end{array}$ & $\begin{array}{l}\text { Language may be unclear } \\
\text { in some parts and some } \\
\text { common mistakes } \\
\text { appear. }\end{array}$ & $\begin{array}{l}\text { It is difficult to read } \\
\text { and understand the } \\
\text { report. There are } \\
\text { some major grammar }\end{array}$ \\
\hline
\end{tabular}




\begin{tabular}{|l|l|l|l|}
\hline & $\begin{array}{l}\text { and only minor } \\
\text { interventions are required } \\
\text { Tables and figures are } \\
\text { correctly referred to in the } \\
\text { running text and have } \\
\text { appropriate captions. } \\
\begin{array}{l}\text { Appropriate sources have } \\
\text { been used and are } \\
\text { correctly referred to in the } \\
\text { text. }\end{array}\end{array}$ & $\begin{array}{l}\text { The great majority of } \\
\text { figures and tables are } \\
\text { correctly referred to in the } \\
\text { running text and have } \\
\text { appropriate captions. } \\
\text { Overall the referencing of } \\
\text { sources is correct but a } \\
\text { few formal mistakes have } \\
\text { been made. The } \\
\text { trustworthiness of some } \\
\text { sources selected may } \\
\text { also be questionable. }\end{array}$ & $\begin{array}{l}\text { issues that have not } \\
\text { been corrected } \\
\text { during the course. } \\
\text { Many figures and } \\
\text { tables are not } \\
\text { correctly referred to } \\
\text { in the running text } \\
\text { and/or miss } \\
\text { appropriate figure } \\
\text { captions. }\end{array}$ \\
& $\begin{array}{l}\text { The referencing of } \\
\text { sources contains } \\
\text { several mistakes, for } \\
\text { instance in terms of } \\
\text { material collected } \\
\text { from sources not } \\
\text { being supported by } \\
\text { references in the } \\
\text { text. }\end{array}$ \\
\hline
\end{tabular}

